\title{
Sexual and reproductive health of women living with HIV in Egypt: Unmet needs and unfulfilled dreams
}

Doaa Oraby

Population Council

Nahla G. Abdel-Tawab

Population Council

Follow this and additional works at: https://knowledgecommons.popcouncil.org/departments_sbsr-rh

Part of the Demography, Population, and Ecology Commons, Family, Life Course, and Society Commons, International Public Health Commons, and the Women's Health Commons How does access to this work benefit you? Let us know!

\section{Recommended Citation}

Oraby, Doaa and Nahla G. Abdel-Tawab. 2014. "Sexual and reproductive health of women living with HIV in Egypt: Unmet needs and unfulfilled dreams," report. Cairo: Population Council. 
$\frac{ \pm}{\frac{2}{2}}$

2 POPULATION

COUNCIL

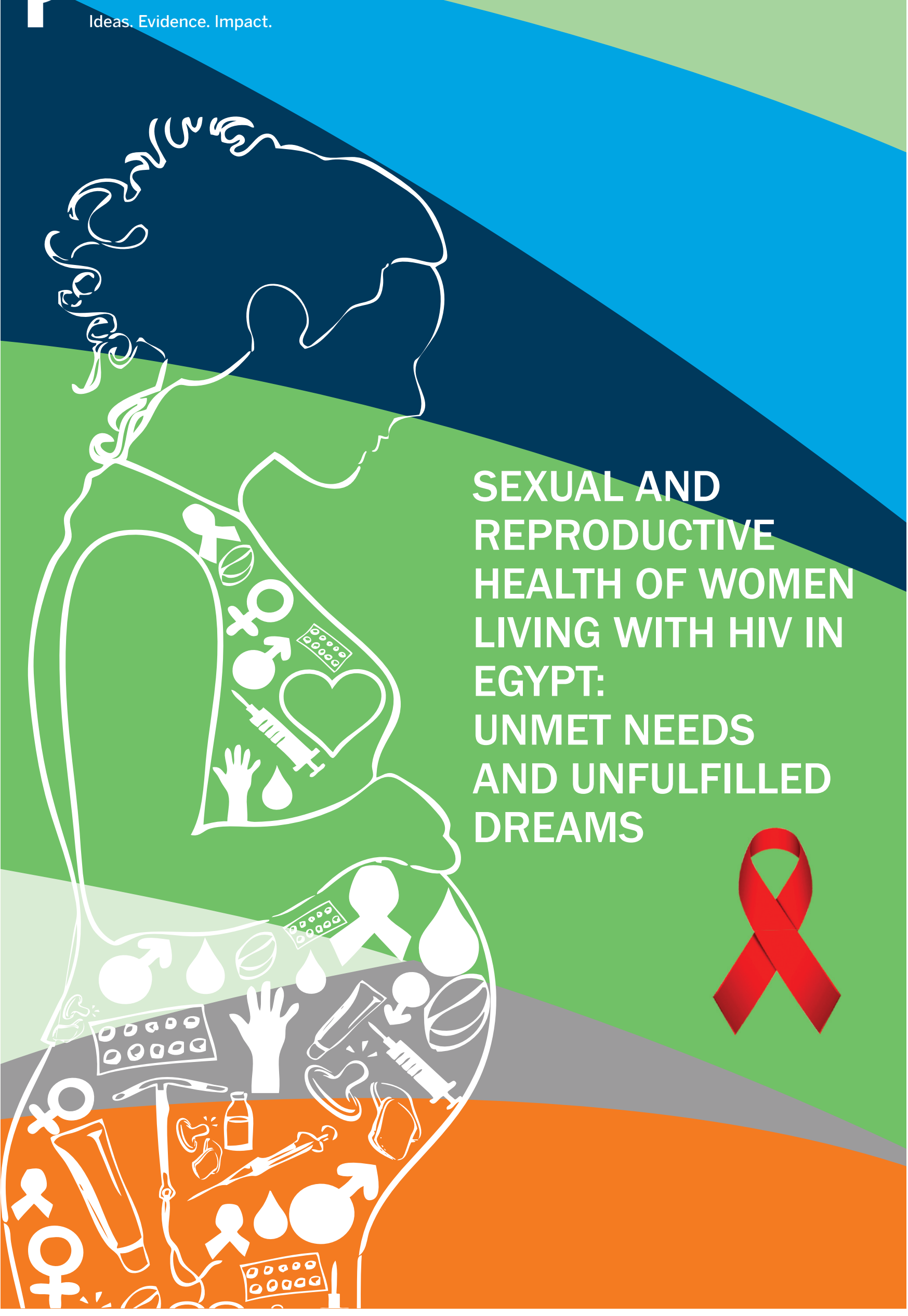





\title{
POPULATION
}

COUNCIL

Ideas. Evidence. Impact.

\section{Sexual and Reproductive Health of Women Living with HIV in Egypt: Unmet Needs and Unfulfilled Dreams}

\author{
Doaa Oraby
}

Nahla Abdel-Tawab 


\section{POPULATION}

COUNCIL

Ideas. Evidence. Impact.

The Population Council confronts critical health and development issues-from stopping the spread of HIV to improving reproductive health and ensuring that young people lead full and productive lives. Through biomedical, social science, and public health research in 50 countries, we work with our partners to deliver solutions that lead to more effective policies, programs, and technologies that improve lives around the world. Established in 1952, and headquartered in New York, the Council is a nongovernmental, nonprofit organization governed by an international board of trustees.

Population Council

One Dag Hammarskjold Plaza

New York, NY 10017

Population Council/Egypt

59 Misr-Helwan Agricultural Road, Maadi

PO Box 168, Maadi

Cairo, Egypt

11431

Tel. +2022525 5968

Fax: +20 225255962

www.popcouncil.org

\section{Suggested citation:}

Oraby, Doaa and Abdel-Tawab, Nahla. 2014. Sexual and reproductive health of women living with HIV in Egypt: Unmet needs and unfulfilled dreams. Cairo, Egypt: Population Council.

\section{Editor:}

Gina Reynolds-Wheeler

Any part of this publication may be photocopied without permission from the publisher provided that copies are distributed without charge and that full source citation is provided. The Population Council would appreciate receiving a copy of any materials in which the text is used. 


\section{Contents}

Acknowledgements ......................................................................................... vi

Abbreviations and Acronyms ............................................................................ vii

Executive Summary .......................................................................................... viii

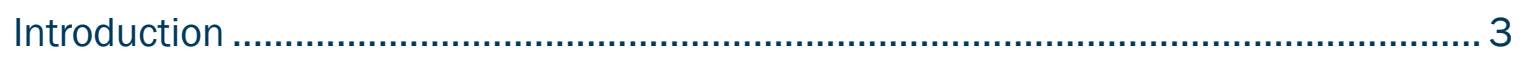

A Life-Changing Event: Receiving an HIV-Positive Diagnosis ....................................... 9

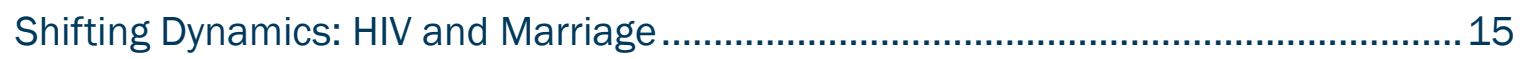

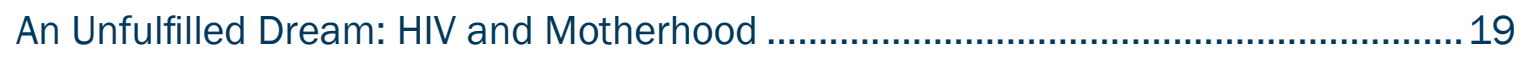

Limited Options: Women Living with HIV and Contraception ....................................... 27

Addressing Sexual and Reproductive Health Needs of Women Living with HIV ...........33

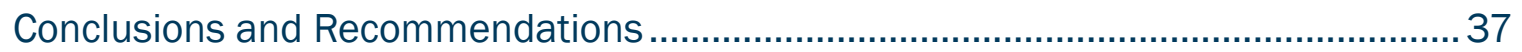

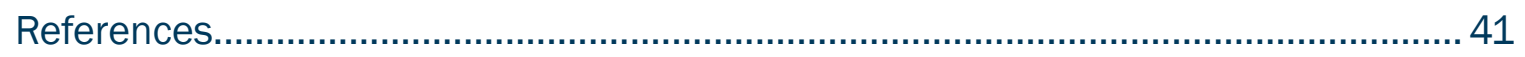




\section{Acknowledgments}

We would like to express our heartfelt thanks to the women and men living with HIV who participated in this study. These individuals provided invaluable information by answering deeply personal questions about their reproductive lives and needs. This study would not have been possible without their contributions.

We also extend our thanks and appreciation to officials at the National AIDS Program, at the Egyptian Ministry of Health and Population, who participated in interviews and who have supported the study and shown keen interest in its results and recommendations.

Additional thanks go to the Population and Family Planning and the Maternal and Child Health sectors at the Egyptian Ministry of Health and Population and to service providers at Caritas (Alexandria), Freedom (Cairo), and Friends of Those with Affected Immune System (Minia) who candidly shared their views regarding the provision of reproductive health services to women living with HIV and who supported data collection in their facilities.

Finally, we extend our thanks to the Ford Foundation for providing financial support for this study and to Dr. Montasser Kamal, Senior Reproductive Health Program Officer, for his support and guidance throughout the implementation of this study.

It is our hope that this study will raise awareness of the unfulfilled sexual and reproductive health needs of women living with HIV in Egypt and will lead to greater access to compassionate and comprehensive services for this special group of women. 


\section{Abbreviations and Acronyms}

$\begin{array}{ll}\text { AIDS } & \text { Acquired Immunodeficiency Syndrome } \\ \text { ANC } & \text { Antenatal Care } \\ \text { ARV } & \text { Antiretroviral } \\ \text { FP } & \text { Family Planning } \\ \text { HIV } & \text { Human Immunodeficiency Virus } \\ \text { IDU } & \text { Injecting Drug User } \\ \text { MCH } & \text { Maternal and Child Health } \\ \text { MENA } & \text { Middle East and North Africa } \\ \text { MOHP } & \text { Ministry of Health and Population } \\ \text { NAP } & \text { National AIDS Program } \\ \text { NGO } & \text { Nongovernmental Organization } \\ \text { PHC } & \text { Primary Health Care } \\ \text { PLHIV } & \text { People Living with HIV } \\ \text { PMTCT } & \text { Prevention of Mother-to-Child Transmission } \\ \text { SRH } & \text { Sexual and Reproductive Health } \\ \text { STI } & \text { Sexually Transmitted Infection } \\ \text { UNAIDS } & \text { Womed Nations Joint Programme on HIV/AIDS } \\ \text { UNFPA } & \text { WhH }\end{array}$




\section{Executive Summary}

The gender profile of the HIV/AIDS epidemic has changed since it emerged 30 years ago when infections were concentrated in key populations of men such as injecting drug users and men who have sex with men. In 2012, women accounted for nearly 50 percent of the estimated 35.3 million people living with HIV/AIDS globally. In the Middle East and North Africa region, 44 percent of infected adults are women. The past 30 years have also witnessed remarkable improvements in access to high-quality information and medical services, including services for prevention of mother-to-child transmission of the virus.

With care and treatment for HIV/AIDS becoming more accessible, women living with HIV have become healthier, live longer, and make plans for a future that includes parenting. While many programs have focused on preventing mother-to-child transmission, the rights of women living with HIV to fulfil their sexual and reproductive health needs have been greatly overlooked.

This study explores the sexual and reproductive health needs of women living with HIV in Egypt and identifies the challenges they face in achieving their reproductive goals. In doing so, this study aims to inform changes to policy and spur new programming that will lead to more comprehensive and compassionate care for women living with HIV.

The study is informed by in-depth interviews with 26 women who are living with HIV, four men who are married to HIV-positive women, 12 health care service providers who work for nongovernmental organizations that provide services to people living with HIV, and six program managers at nongovernmental organizations and the Ministry of Health and Population. The interviews reveal important insights into the unfulfilled reproductive and sexual health needs of women living with HIV in Egypt and the challenges faced in accessing health services.

The sexual and reproductive needs and desires of women living with HIV in Egypt may be no different than those of healthy women in Egypt or other parts of the world. Women living with HIV in Egypt want to have safe and enjoyable sexual relations with their husbands, give birth to healthy children, and avoid unintended pregnancy. However, these women face considerable challenges to the exercise of their sexual and reproductive rights and the achievement of their fertility goals.

Stigma and discrimination acutely affect their access to comprehensive SRH services. Unless women living with HIV are referred to selected private doctors who are aware of their status and are willing to take on HIV-positive cases, those who seek care at public facilities are treated with disrespect or even denied services. Health care providers who provide support and 
counseling to women living with HIV focus exclusively on condom use and risk reduction but seldom discuss the women's fertility desires or counsel them on pregnancy, contraception, or prevention of mother-to-child transmission of HIV. Negative experiences with the health care system prevent women living with HIV from seeking health care and expose them to additional health risks.

The vertical structure of health service delivery in Egypt results in providers being unable to provide services outside their domain. HIV/AIDS care givers are not trained in providing for the sexual and reproductive health needs of women living with HIV, while primary and secondary care providers who offer reproductive health services stigmatize women living with HIV and are not aware of their needs.

However, this reality can be changed. The change can begin by linking sexual and reproductive health services for women living with HIV with HIV care. Linking these two critical components of care will create a more comprehensive package of health services for women living with HIV. In the meantime, operations research is needed to identify the most feasible, acceptable, and cost-effective model for integrating these services in a low-prevalence country like Egypt where HIV infection is highly stigmatized.

Training of health care providers and raising public awareness about HIV are essential for reducing stigma and discrimination against women living with HIV. Finally, women living with HIV need to be empowered to stand up for their sexual and reproductive health rights and to demand quality services. 



\section{It is important to support the}

rights of all women, including women living with $\mathcal{H} I \mathcal{V}$, to make informed choices about their reproductive lives.

(WHO and UNFPA 2006a) 


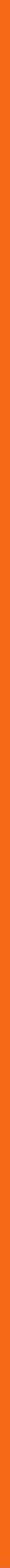




\section{Introduction}

The gender profile of the HIV/AIDS epidemic has shifted dramatically over the last 30 years from being a disease that is concentrated among key populations of men such as men who have sex with men and injecting drug users to one that is affecting both women and men. In 2012, nearly half of the estimated 35.3 million people living with HIV were women and one in every two new adult HIV infections occurred among women (UNAIDS 2014). In the Middle East and North Africa (MENA) region, 44 percent of adult people living with HIV (PLHIV) are women (UNAIDS 2013). Women in the MENA region are being infected directly through the use of injectable drugs or working as sex workers, or indirectly as the sexual partners of injecting drug users or men who have sex with men (UNAIDS 2012).

Like most countries of the MENA region, Egypt has low HIV prevalence, which stands below 0.02 percent among the general population (Ministry of Economic Development and UNDP 2010) with higher prevalence rates documented among key populations of men (Ministry of Health and Population 2010). Although there are no national statistics that document the rising prevalence among women in Egypt, anecdotes by service providers in Voluntary Counseling and Testing centers suggest an increase in the number of women infected with HIV.

With care and treatment for HIV/AIDS becoming more accessible in many countries, women, men, and young people living with HIV are feeling healthier, living longer, and planning for their futures, including making decisions about starting or expanding a family (Perchal, Farrell and Osborne 2006). PLHIV may want to have children, in order to prove their fertility or to leave someone behind to carry the family's name after they die. Others may decide to delay or stop childbearing but fail to achieve this goal as a result of limited access to contraceptive information and services.

Women living with HIV (WLHIV) have the same sexual and reproductive rights as all other women, including rights to information, rights to adequate services, and rights to make free and informed decisions about reproduction. ${ }^{1}$ All too often, programs in many parts of the worldincluding Egypt-have failed to recognize these rights. Most HIV/AIDS intervention programs have focused largely on preventing mother-to-child transmission (PMTCT), while overlooking the rights of WLHIV to fulfill their sexual and reproductive health (SRH) goals. Not surprisingly, WLHIV are often unaware of measures to reduce the risk of transmission of infection to their children; couples needing assistance with reproduction usually fail to secure a doctor who will

\footnotetext{
1 The 1994 International Conference on Population and Development Program of Action defines reproductive health rights as "the right of individuals and couples to decide the number and spacing of their children and to have the information and means to do so; the right to the highest attainable standard of sexual and reproductive health; the right to make decisions concerning reproduction free of discrimination, coercion and violence, and the right to control all aspects of one's sexuality, including sexual and reproductive health free of discrimination, coercion, and violence" (UNFPA 1994).
} 
help them achieve pregnancy; and in some cases HIV-positive women are pressured by health care providers to undergo sterilization so that they cannot give birth to HIV-infected children (UNAIDS 2012).

Research from countries in the MENA region suggests that there is an unmet need for SRH services by WLHIV, including family planning, antenatal care, delivery, postpartum care, and guidance on prevention of mother-to-child transmission (PMTCT) (UNAIDS 2012). However, not enough is known about the fertility desires and SRH needs of WLHIV in Egypt. Moreover, little is known about the extent to which health care professionals who provide HIV/AIDS services are aware of and are willing to support those needs. Learning more about the SRH needs of WLHIV in Egypt and the services available to them is critically important to improving the quality of services and the lives of those women and their families.

This study explores the needs and experiences of WLHIV in Egypt in order to inform future policies and programs to support their sexual and reproductive rights and goals. A qualitative methodology was implemented whereby in-depth interviews were conducted with three categories of respondents. The first category included 26 WLHIV and four men married to WLHIV. The second category comprised 12 health care providers affiliated with nongovernmental organizations (NGOs) that provide care for PLHIV. The third category included three program managers at the Ministry of Health and Population (MOHP) and three managers of NGOs that provide services to PLHIV.

Most of the WLHIV and husbands of WLHIV were recruited with assistance from NGO contacts in Alexandria, Cairo, and Minia. Others were recruited through respondent-driven sampling, that is, PLHIV who participated in the study invited other PLHIV to participate. Data collection was conducted by trained male and female interviewers.

The study protocol was reviewed and approved by the Population Council Institutional Review Board. Informed consent was sought from the participants before conducting the interviews and regular monitoring visits were conducted by Population Council staff to ensure full compliance with ethical principles and protection of research participants and confidentiality of data.

The WLHIV who participated in the study were between the ages of 22 and 40 years old. Most had completed a secondary education or higher. Of the 26 WLHIV interviewed for the study, 18 were married to HIV-positive men, five were married to HIV-negative men, two were divorced, and one was widowed. The majority of WLHIV had children who are HIV-negative (20 out of 26), while two had HIV-positive children. Four WLHIV did not have any living children. Male 
respondents were between 30 and 43 years of age. Three had completed a secondary education and one had university-level education. Three of the male participants were HIV-positive. One man was unemployed.

The health care providers interviewed for this study included two doctors, two nurses, five counselors, two program coordinators, and one outreach worker. They work for NGOs based in Alexandria, Cairo, and Minia. The majority of health care providers who were interviewed in this category were women aged 26 to 61 years old. They possessed between 2 and 18 years of experience managing HIV/AIDS cases.

The study also included interviews with program directors and managers of the partner NGOs (Freedom in Cairo, Caritas in Alexandria, and Friends of Those with Affected Immune System in Minia) and MOHP officials. Participants from the MOHP included the Population and Family Planning Sector Undersecretary, the Maternal and Child Health Sector Director, and the National AIDS Program (NAP) Director. 



\section{They told me over the phone that me and my daughter had the virus... I started screaming 'Why me?}

(WLHIV, 36 years)

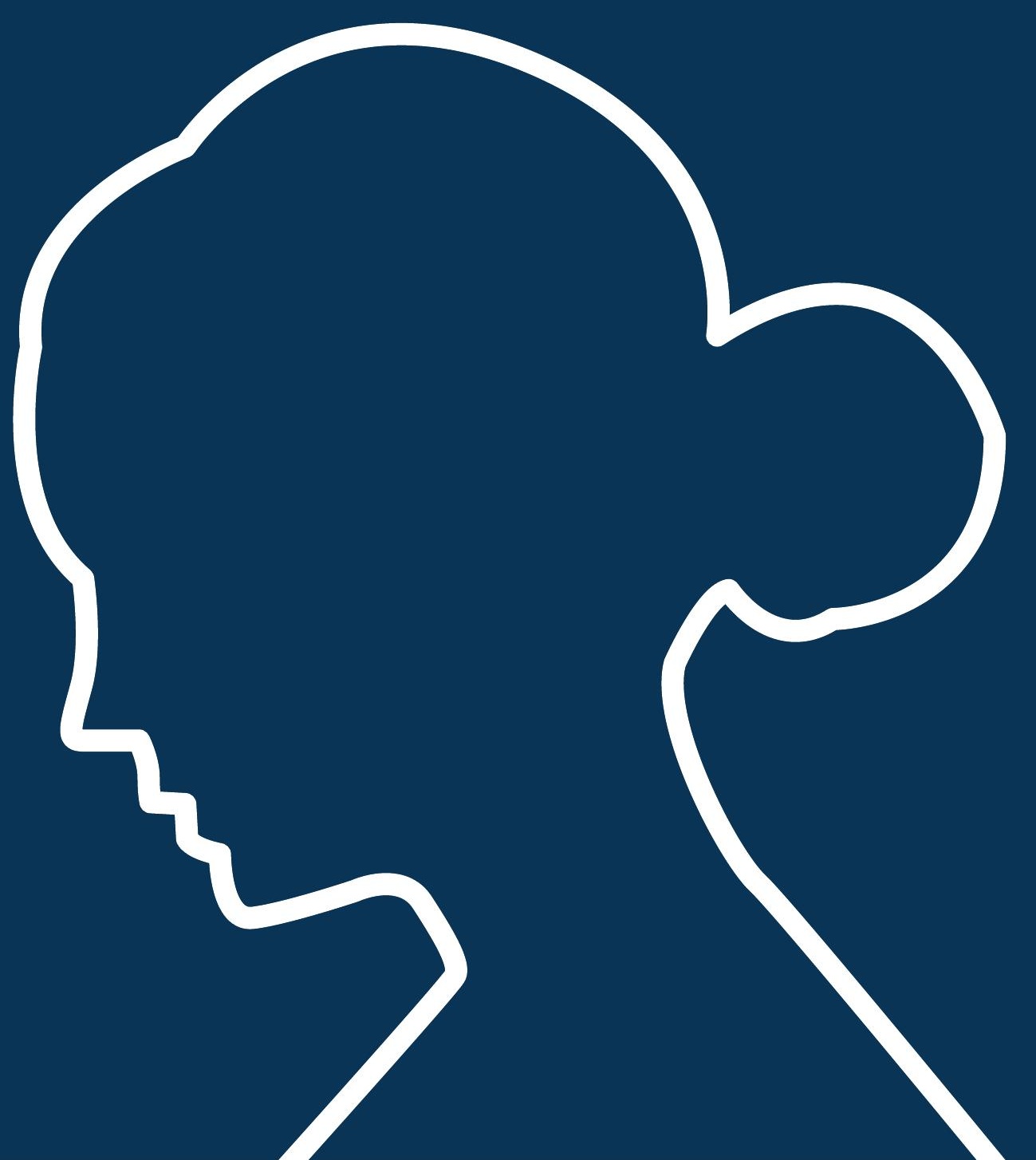





\section{A Life-Changing Event: Receiving an HIV-Positive Diagnosis}

Finding out that one is HIV-positive is often a shocking and devastating experience. Due to the high level of stress involved in receiving this news, compassionate care and counseling provided by a well-trained health care professional may be the only effective means to mitigate the devastating shock of an HIV-positive diagnosis. Individuals who undergo HIV testing should ideally receive pre- and post-test counseling whereby pretest counseling helps them understand the significance of the HIV test and the results while post-test counseling helps them cope with their new status in case of a positive result. Additionally, post-test counseling for an HIV-positive diagnosis should help those diagnosed disclose their HIV status to their sexual partners and inform them about safe sex, including access to condoms. Post-test counseling should be followed by referrals to specialized HIV-care providers (WHO and UNFPA 2006b).

According to Egypt's National AIDS Program (NAP) guidelines, HIV test results should be provided by a trained counselor during a post-test counseling session and results must be provided face-to-face, and not over the phone or through other persons (NAP 2013).

Several of the WLHIV interviewed for this study said that they were diagnosed after their children became ill and tested positive for HIV. However, most women said that they were diagnosed as HIV-positive after learning that their husbands had tested positive during routine HIV screening for visa applications, preoperative procedures, or in response to an unexplained fever or illness. A few of the WLHIV reported being married to men who practiced high-risk behaviors, such as injecting drug use. While these women were aware of their risk for contracting $\mathrm{HIV}$, they reported feeling helpless to protect themselves due to their lack of autonomy and inability to influence their husbands' behavior.

Almost all of the interviewed women received neither pre- nor post-test counseling, but were informed of their HIV diagnosis by providers who lacked critical knowledge and skills of how to handle the shock and confusion associated with receiving an HIV-pos-

4 The laboratory technician told me my HIV diagnosis over the phone,

(WLHIV, 28 years) itive diagnosis. The fact that some women were given the devastating news that they were HIV-positive over the phone illustrates how poorly prepared these providers were to handle such a sensitive conversation. Women also revealed that providers who informed them of their HIV diagnosis did not possess the counseling 
skills necessary to mitigate the shock and fright these women experienced upon learning of their diagnosis. In some cases, health care providers even stigmatized these women by accusing them of engaging in inappropriate behavior. One woman reported that, instead of showing sympathy and providing information about HIV and the services available to her, the laboratory technician insisted on knowing her marital status and sexual practices. “So, how did you get the disease?" the lab technician asked after learning the woman was not married.

Following diagnosis, several WLHIV were advised to contact NAP for specialized HIV care and support services. However, several of those women said that the poor care and the stigma they were subjected to at the time of their HIV diagnosis caused them to hesitate to disclose their HIV-positive status and seek follow-up care at NAP. The situation was so overwhelming for one participant who reported that it took her a year to gather the strength to contact NAP staff (see Case Study 1).

In the days and weeks following their diagnosis, many women reported suffering panic attacks and being unable to manage their personal health. Some feared the reactions of their loved ones. For example, one woman reported feeling high levels of stress because she was worried that her husband would abandon her when he learned of her

4 At first I was devastated, lost weight, and got severe anemia. I had a blood transfusion but God helped me and I am much better now.

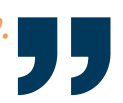

(WLHIV, 30 years) diagnosis.

The stories these women told about the experiences that led to and accompanied their HIVpositive diagnosis echo findings from research about WLHIV from countries across the MENA region. For many women, diagnosis with HIV comes suddenly and unexpectedly and triggers depression that negatively affects their health-seeking behavior. Unaware of the possibilities of treatment and long-term survival, an HIV diagnosis to these women was equivalent to receiving a death sentence (UNAIDS 2012). WLHIV are often blamed for their condition despite the fact that most WLHIV reported that they were infected by their husbands (Khattab et al. 2010).

Stigma experienced by WLHIV adds to the illness burden in various ways and may delay appropriate help-seeking for treatable health problems. Women fear the external and internal stigma they will face that will change their lives for good (Khattab et al. 2007). External stigma refers to the dynamic process of devaluation that scandalizes an individual in the eyes of others (Goffman 1963), while internal stigma is felt or imagined self-stigmatization produced by internalization of shame, blame, guilt, and fear of discrimination associated with being HIVpositive (Brouard and Wills 2006). 


\section{Case Study 1: Mona}

Mona was diagnosed as being HIV-positive following the diagnosis of her one-year-old daughter. These diagnoses devastated Mona and her family. Her daughter died as a result of an HIV-related illness. Mona's husband, who tested HIV-negative, distanced himself from her even after learning about safe-sex practices from their health care provider. Eventually, Mona and her husband divorced.

Following her divorce, Mona became very lonely and depressed as she did not know any other people who were HIV-positive. Finally, she met a man who was also HIVpositive and who introduced her to support groups where she met other PLHIV. Meeting these people helped Mona see that she was not alone. She also saw that many of these people were feeling healthy and continuing with their lives. Some even got married and had HIV-negative children. This gave Mona renewed hope: "I asked the two women who had kids [in the support group], 'Can I be a mother again?' and they said, 'Why not? We are mothers.' Since then I [have] believed that I have a role in life and I have to live. I looked after myself and improved because of that hope."

Mona is now 30 years old and is getting ready to marry a man who is also HIV-positive. Her main motivation for getting married is to become pregnant and have a child. Mona worries that they will not be able to have a child if they continue to follow the doctor's advice to use condoms. "I am keen to ask about the sexual relations with my husband to be," she stated. "I want to get pregnant, [but] how and when to use a condom and when not to use one?" She also fears that she will be poorly treated by hospital staff if she is able to get pregnant, saying "I do not want to go to the doctor [for pregnancy care]. I asked other WLHIV and all of them went through drama at the time of delivery." 



\section{Our relationship definitely got}

affected as I felt guilty towards her... I feel there is a psychological barrier between me and her.

(WLHIV, 30 years)

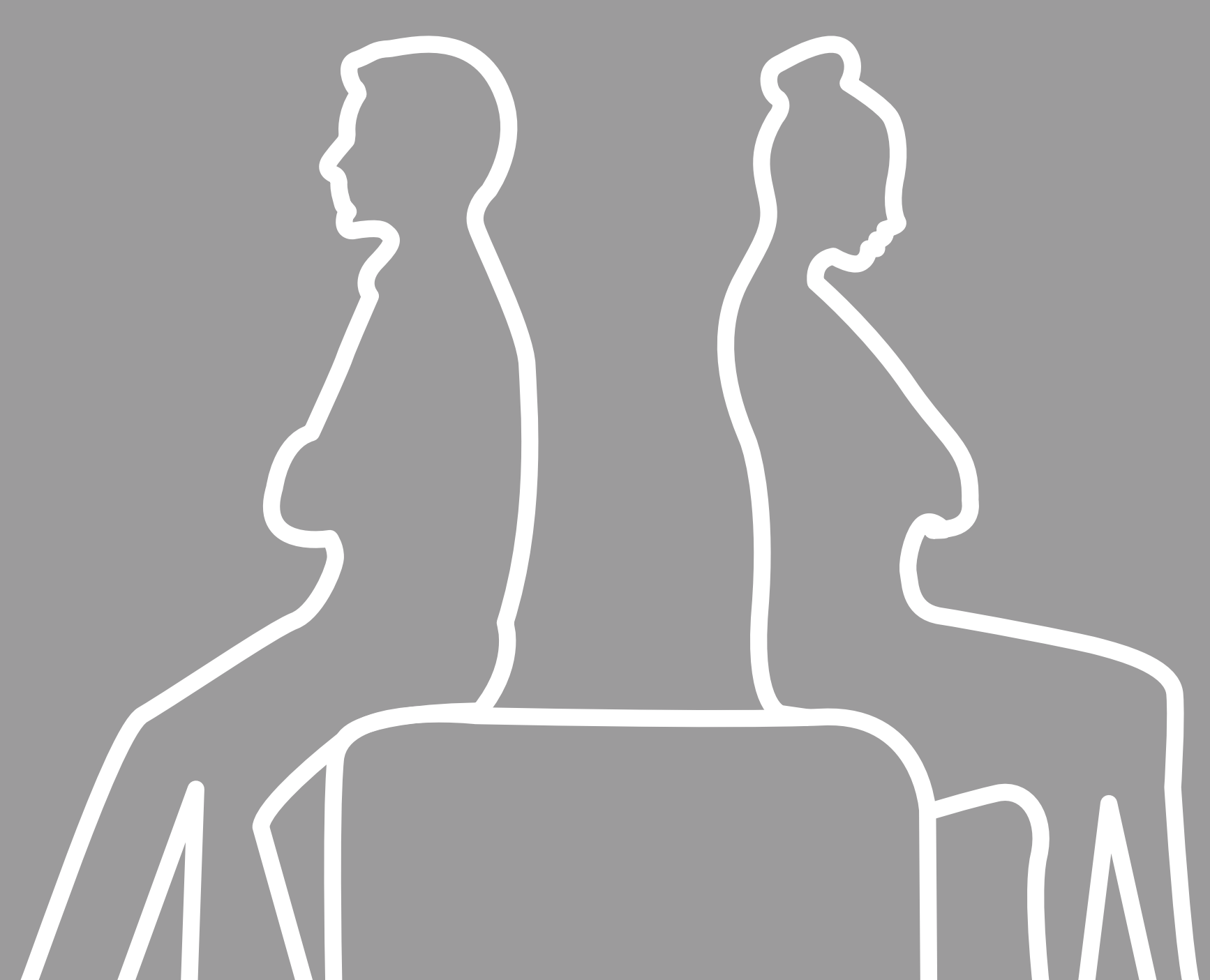





\section{Shifting Dynamics: HIV and Marriage}

A woman's HIV-positive diagnosis can complicate her marriage. These complications manifest themselves in changes to the dynamics of the emotional and sexual relationships between husband and wife, hence straining the marriage. Fortunately, positive emotional support from her husband often helps a woman living with HIV face her diagnosis and take charge of her health.

When asked about their husbands' reactions to their HIV-positive diagnosis, women described a range of responses. Some women said that their husbands reacted angrily, became detached, or got aggressive. One woman said that her worst fear came true; unable to cope with her diagnosis, her HIV-negative husband succumbed to pressure from his family and divorced her. Many women attributed the negative reactions and behaviors of their husbands to feelings of guilt for having transmitted the virus to their wives. In instances when WLHIV blamed their husbands for the infection, the resentment was mutual.

In general, most respondents reported receiving positive emotional support and understanding from their husbands. These women attributed their husbands' positive responses to the fact that they were also living with HIV. A shared HIV-positive diagnosis meant that they now faced life with HIV as a couple.

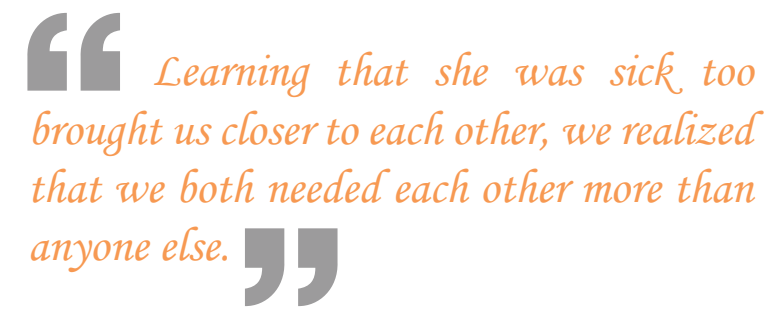

(HIV-positive man, 40 years)

Despite receiving positive emotional support from their partners, sexual intimacy among WLHIV was negatively affected by their HIV diagnosis. Women who blamed their husbands for transmitting the HIV infection to them reported high levels of sexual dissatisfaction and animosity toward their husbands. Some even refused to have physical contact with their husband for up to a year. For other women, the fear of condom rupture during sex, husband's refusal to use condoms and the resulting anxiety about transmitting the infection to their HIV-negative husband, in addition to allergic reactions to condoms, caused high levels of sexual dissatisfaction and emotional stress.

Although all WLHIV indicated that they were advised by health care providers to use condoms, many reported not being counseled by their health care provider about the side effects of condom use (e.g., allergic reactions and vaginal dryness). Because women were not told how to treat or counteract these side effects, they often reported having less sex. 
Sexually transmitted infections (STIs) can also cause pain and discomfort during sex thus leading women to avoid sex and further exacerbating their marital problems. Appropriate and prompt treatment of STIs reduces the risk of transmitting HIV to sexual partners, can prevent the reproductive-tract and obstetric complications associated with STIs, and offers a unique opportunity to provide women with comprehensive care and counseling that can improve their sexual and reproductive health and well-being (WHO and UNFPA 2006b). However, as WLHIV fear disclosing their HIV-positive status to health care providers because of stigma and discrimination, they frequently do not seek treatment for STIs hence become exposed to more health risks and complications in addition to a disturbed sexual relationship.
I wear a condom every time and this makes it very painfulfor her because of the dryness ... our encounters have become less frequent than before,

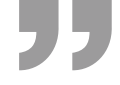

(HIV-positive man, 39 years)

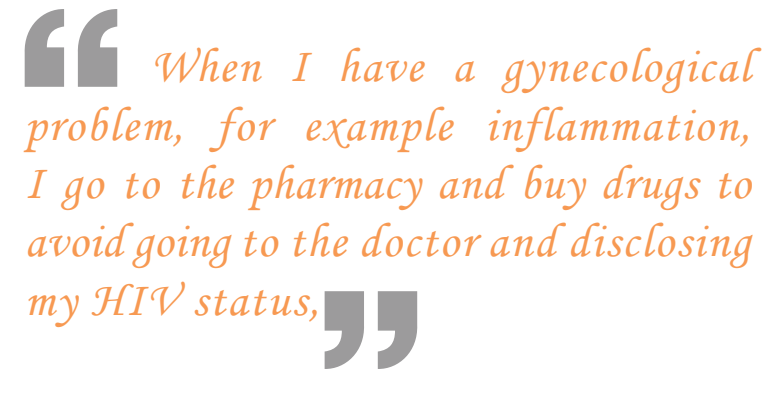

(WLHIV, 33 years)

The experiences and challenges described by participants in this study resemble those described by WLHIV from countries across the MENA region. Many WLHIV in the MENA region reported experiencing sexual problems following HIV diagnosis. Some women attributed these problems to believing that sex was the cause of their infection, while others were afraid of transmitting the infection to their sexual partners. Those who contracted the virus through sex said they developed a psychological barrier against having sex again, while those undergoing antiretroviral (ARV) therapy attributed their loss of sexual desire to treatment side effects. Unfortunately, very few of those women received counseling or advice on how to address their sexual problems (UNAIDS 2012). 
4 Awoman infected withHIV definitely does not feel like any other normal person who can get pregnant and deliver at any time. She feels incomplete.

(WLHIV, 30 years)

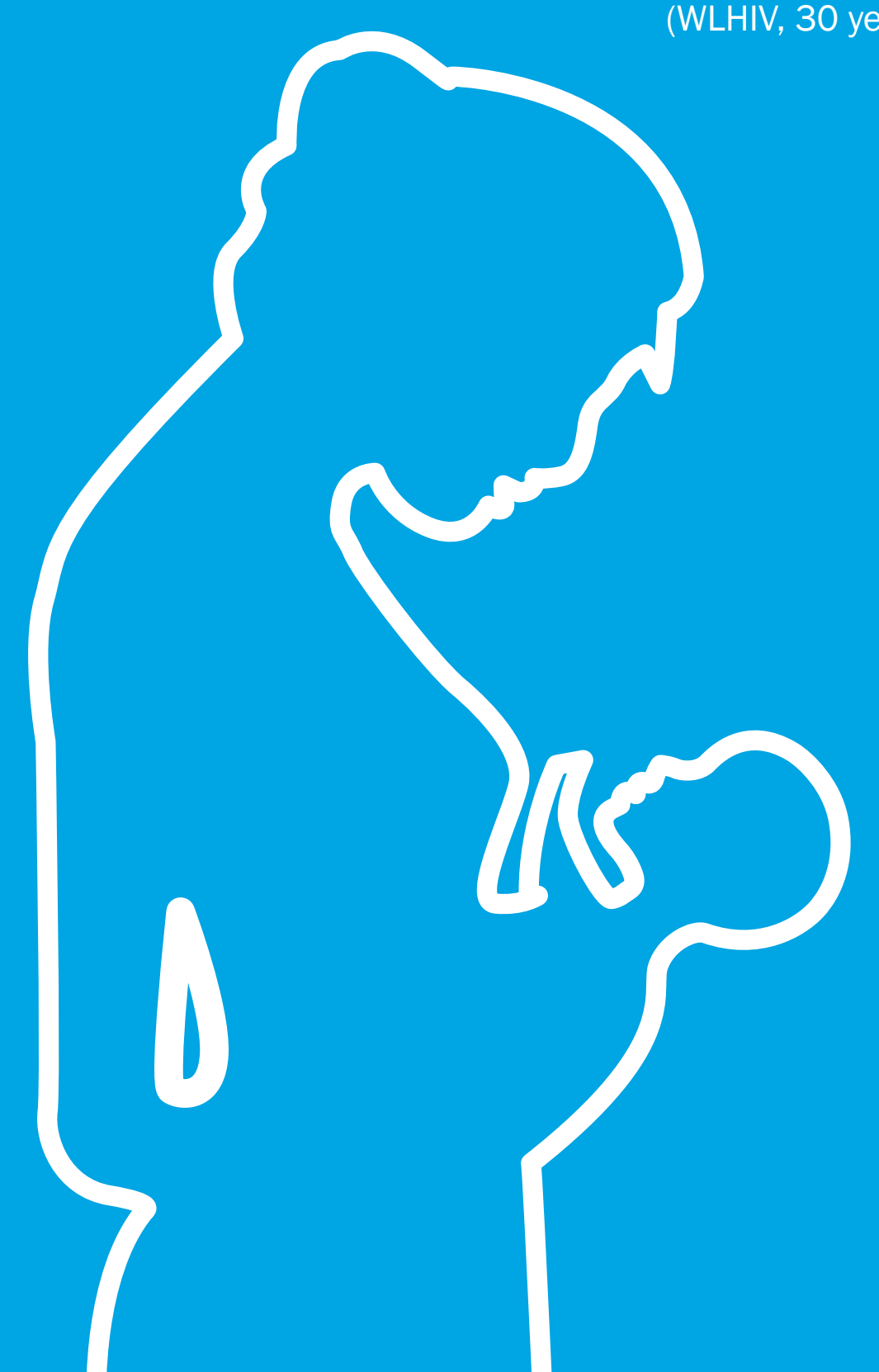




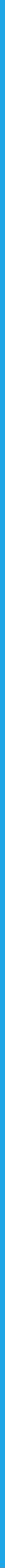




\section{An Unfulfilled Dream: HIV and Motherhood}

Women living with HIV may experience lower fertility as a result of reduced sexual activity, a concurrent STI, or the negative impact of HIV infection on her fertility and that of the male partner (WHO and UNFPA 2006b). Also, WLHIV are more vulnerable than others to pregnancy complications, such as infections, blood loss, anemia, bacterial pneumonia, and preterm labor (Anderson 2001). Improving access to quality SRH services is essential to minimizing these risks and increasing the likelihood of a healthy pregnancy and delivery. Interventions for preventing the transmission of HIV from mother to child are remarkably effective. In the absence of prevention of mother-to-child transmission (PMTCT) interventions, the risk of motherto-child transmission of HIV is 20-45 percent (WHO and UNFPA 2006b). However, the risk of mother-to-child transmission can be reduced to less than 2 percent with a package of evidence-based interventions including antiretroviral (ARV) prophylaxis given to women and to the infant combined with elective cesarean section and avoidance of breastfeeding if artificial feeding is feasible (WHO 2010).

Facilitating easy access to quality SRH services is essential to supporting the desires of WLHIV to achieve their reproductive goals. Yet several studies have documented that easy access to SRH services is not universal for WLHIV (Ingram and Hutchinson 2000; Mahendra et al. 2007; Population Council 2007; Christiana et al. 2008; Gruskin et al. 2008; Myer et al. 2010; MacCarthy et al. 2012). Facilitating easy access to quality SRH services for WLHIV is essential to supporting these women's desires to achieve their reproductive goals. Research evidence indicates that only about 5 percent of pregnant WLHIV in the MENA region receive the care they need (UNAIDS 2012). Most interviewed WLHIV reported not receiving pregnancy-related information from their health care providers. In almost all cases, WLHIV had initiated discussions with their health care providers about pregnancy and their desire to have more children, rather than the providers taking the leading role. The latter tended to focus on counseling for reducing transmission risk and condom demonstration and seldom discussed the fertility desires or reproductive health needs of these women. In some cases, the women reported that their health care providers denied them their reproductive rights by discouraging them from becoming pregnant.

Many of the WLHIV interviewed were not aware of recommended interventions for PMTCT. Their fear of transmitting the virus to their children made them not want to get pregnant. A few women said that they considered having an abortion to avoid giving birth to an HIV-infected child.

Unfortunately, there are no comprehensive education programs for PLHIV to educate them [women] about what to do and what not to do from the moment they decide to have a child until the child is 6orn and weaned,

(HIV-positive man, 42 years) 
Despite these fears and challenges, some WLHIV said that they had changed their mind about having children after attending support groups. They added that at these meetings they learned about effective PMTCT interventions and met other WLHIV who got pregnant and delivered HIV-negative children. After participating in these support

4. I wanted to become pregnant, I asked the doctor at the $\mathcal{N A P}$ who told me about a way that could help me become pregnant.

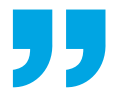

(WLHIV, 34 years) groups, WLHIV said that they felt optimistic about their fertility options and had a renewed desire to become pregnant.

This renewed optimism had multiple sources. Some women said that they were eager to add a new member to their families who could support their other children. Others said that they wanted to prove that they were just like any other women and could have normal children despite their HIV diagnosis. In fact, research from the MENA region and elsewhere around the world suggests that a woman's knowledge of her HIV-positive status has little effect on her desire to get pregnant or on her decision to terminate a pregnancy (EngenderHealth and UNFPA 2006; Population Council 2007; UNAIDS 2012). In 2012, an estimated 1.5 million pregnant WLHIV lived in low- and middle-income countries (UNAIDS 2014). Availability of ARVs and measures to prevent vertical transmission encouraged WLHIV to become pregnant, experience healthy pregnancies, and deliver healthy, HIV-negative children (VOPW 2004).

However, a key concern for WLHIV who wanted to become pregnant was how to get pregnant while using condoms. Women were advised to have unprotected sex at the time of the month when they expected to be ovulating. Also, they were advised to attempt pregnancy when their viral load was lowest or undetected. However, according to one service provider, the cost of measuring viral load in order to determine the right time for pregnancy is so high that many WLHIV cannot afford it.

HIV-infected women who are married to uninfected men face a greater challenge in trying to get pregnant while minimizing the risk of transmitting the virus to their husband. For those couples, the safest option is artificial insemination (i.e., semen is inserted directly into a woman's cervix, fallopian tubes, or uterus using a wide syringe), but again very few can afford the cost. One woman reported that she received guidance from a NAP official on performing home-based artificial

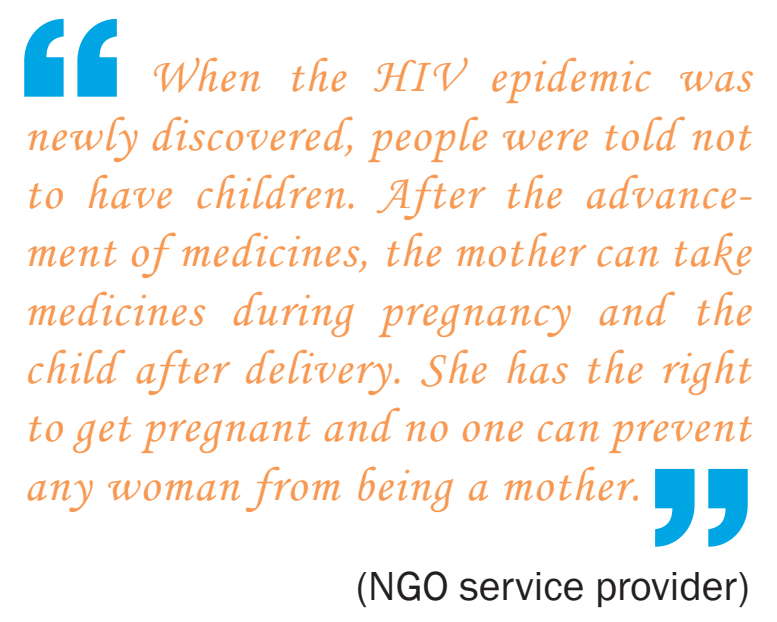

insemination, drawing the semen from a used condom and injecting it into her vagina. 
The interviewed health care providers were generally supportive of the rights of WLHIV to have children. Some of the service providers described the guidance they give to WLHIV who want to get pregnant, which largely aligns with international best practices. They inform WLHIV about the risks of mother-to-child transmission of HIV, advise them to monitor their viral load before attempting pregnancy, and refer them to NAP to receive the required ARVs during pregnancy.

Some women confirmed receiving accurate information and guidance from health care providers, however not all WLHIV benefited from these resources. Some told agonizing stories of rejection by healthcare providers. A third woman said her health care provider scolded her for getting pregnant and gave her a medication which she believed induced an abortion (see Case Study 2).

4 I followed up my pregnancy with different doctors. Every time I told the doctor that I am HIV-positive, I was denied the service stating that there were other places that I could follow up my pregnancy at, but not their clinic.

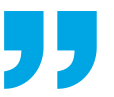

(WLHIV, 32 years)

C. I almost saw 15 doctors

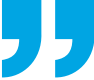

(WLHIV, 31 years)

\section{Case Study 2: Ola}

Ola's dream is to be a mother. Ten years ago, shortly after she married, she became pregnant and miscarried after six months. Ola carried her second pregnancy to term and delivered a beautiful baby girl. When Ola's daughter was three months old, her health began to deteriorate. It took nine months and many medical visits for doctors to discover what was causing the illness. Ola's daughter was HIV-positive. Three months later, Ola's daughter died.

Ola and her husband were tested for HIV. Ola was found to be HIV-positive and her husband was HIV-negative. Initially, Ola hesitated to seek treatment because she was afraid to lose her daughter. It took Ola several months after her daughter's death to recover and seek treatment.

Ola's husband has been very supportive and continues to reassure her that he will not divorce her. "He is considerate not to upset me as he knows stress lowers immunity." The couple received counseling from NAP officials on safe sex and Ola's husband is comfortable with continued sexual contact. Despite this, Ola's diagnosis has had a negative effect on their intimate relationship. Ola is afraid of transmitting HIV to her husband and her sexual desire has decreased. 
Ola hopes that she and her husband will be able to have children. She has sought advice from her NAP doctor who gave her information on home-based artificial insemination. She remembered, "I was eager to get pregnant and asked the doctor [about it]. He advised me to withdraw semen from the condom using a syringe and then inject it vaginally. We kept doing that for one year until I finally got pregnant."

When she sought antenatal care at an NGO clinic without disclosing her HIV status, Ola was treated well by the staff and provided with quality care. However, when she was four months pregnant Ola developed a skin rash and mouth thrush. This led her to seeking treatment from a public doctor who reprimanded her and told her that by becoming pregnant while HIV-positive she was destroying herself and dooming her baby to die. He prescribed medication and shortly after taking it Ola developed bleeding and suffered a miscarriage.

Ola does not know if the medication deliberately caused the miscarriage, but her NAP doctor later told her that it should not be given to a woman who is pregnant or trying to become pregnant. She went to a university hospital to receive a dilation and curettage procedure to remove the remaining fetal and other matter from her uterus. She did not disclose her status to the staff there. Instead she told them that she had Hepatitis C. The doctor initially refused to provide the service, but her NAP doctor was able to convince them to reconsider.

In the two years since her last miscarriage Ola has been trying to get pregnant-without success. She is now 36 years old and does not know if she will ever be able to become pregnant. She has found it difficult to locate a doctor willing to provide her with fertility assistance, telling her interviewer, "It is hard to find a doctor who would accept us and would be willing to deal with us."

The most formidable challenge for WLHIV is finding a place for safe, clean, and dignified delivery given the prevalent stigma and discrimination among health care providers against PLHIV. Both WLHIV and service providers told heartbreaking stories of WLHIV who were denied services, treated with neglect, or humiliated once they disclosed their HIV status. Several WLHIV reported that they were unable to find a doctor willing to perform a cesarean section and ended up delivering vaginally with no medical assistance.

$\mathcal{N}$ ot one of them accepted to deliver me after I disclosed my HIV status,

(WLHIV, 29 years) 
Women who did not disclose their HIV status often failed to convince their doctors to deliver them via cesarean section when there was no clear obstetric indication. One woman reported that even with a NAP official advocating on her behalf, the doctor still refused to perform a C-section.

Some NGOs that support PLHIV refer women to selected private health care providers who are willing to deal with PLHIV, albeit for an extra fee. Two WLHIV were referred to private providers through an NGO that actually paid for the health care they received. However, this type of financial support is not always available, thus the expense is eventually borne by the WLHIV.

Almost all of the WLHIV who participated in this study were aware of the possibility of HIV transmission to the newborn through breast milk. They indicated that they received guidance from NAP officials to formula-feed their infants, however formula is expensive, costing approximately 48 EGP (\$7) per container, thus presents a financial burden for many WLHIV. Although MOHP officials confirmed that subsidized formula is available to WLHIV from primary health care centers, not all WLHIV are aware of this resource. Furthermore, to receive the subsidized formula a woman must provide proof of her HIV-positive status to the health care provider at the PHC center, something which most WLHIV avoid for fear of experiencing further discrimination and stigma. Additionally, justifying artificial feeding and its high cost to their families was a challenge reported by many women.

Caring for an HIV-positive child is an additional burden that WLHIV may have to bear, especially when PHC providers are not informed about the proper care of HIV-positive children. WLHIV who gave birth to HIV-infected children complained about the insensitive behavior of providers and a general lack of ranged with a doctor in a private hospital but when she arrived there he denied he was there... She called me and I told her to take a taxi and meet me at the other hospital... It was too hot and there was too much traffic... By the time she got there and we did her paperwork, the baby came have a C-section.

(NGO Service provider)

4. If he normally charges L.E. 1000 a WLFIV L.E. 2000 (\$280), כ

(WLHIV, 33 years)
4 She was very poor... We had arout vaginally when she was supposed to (US\$140) for a C-section, he would charge 
information about how to manage their children's condition. Moreover, these women face the dilemma of how to explain to their siblings and their families why their newborn child is taking medications. Concerned about the potential side effects of ARVs on their children and about suspicions by their families about the child's medical condition, some WLHIV choose to stop giving ARVs to their children. 
41 I would like to take out the IUD because it is causing me back pain... I don't know where to go to I don't want to do harm to healthy people... in the meantime there is no gynecologist at the fever hospital.

(WLHIV, 38 years)
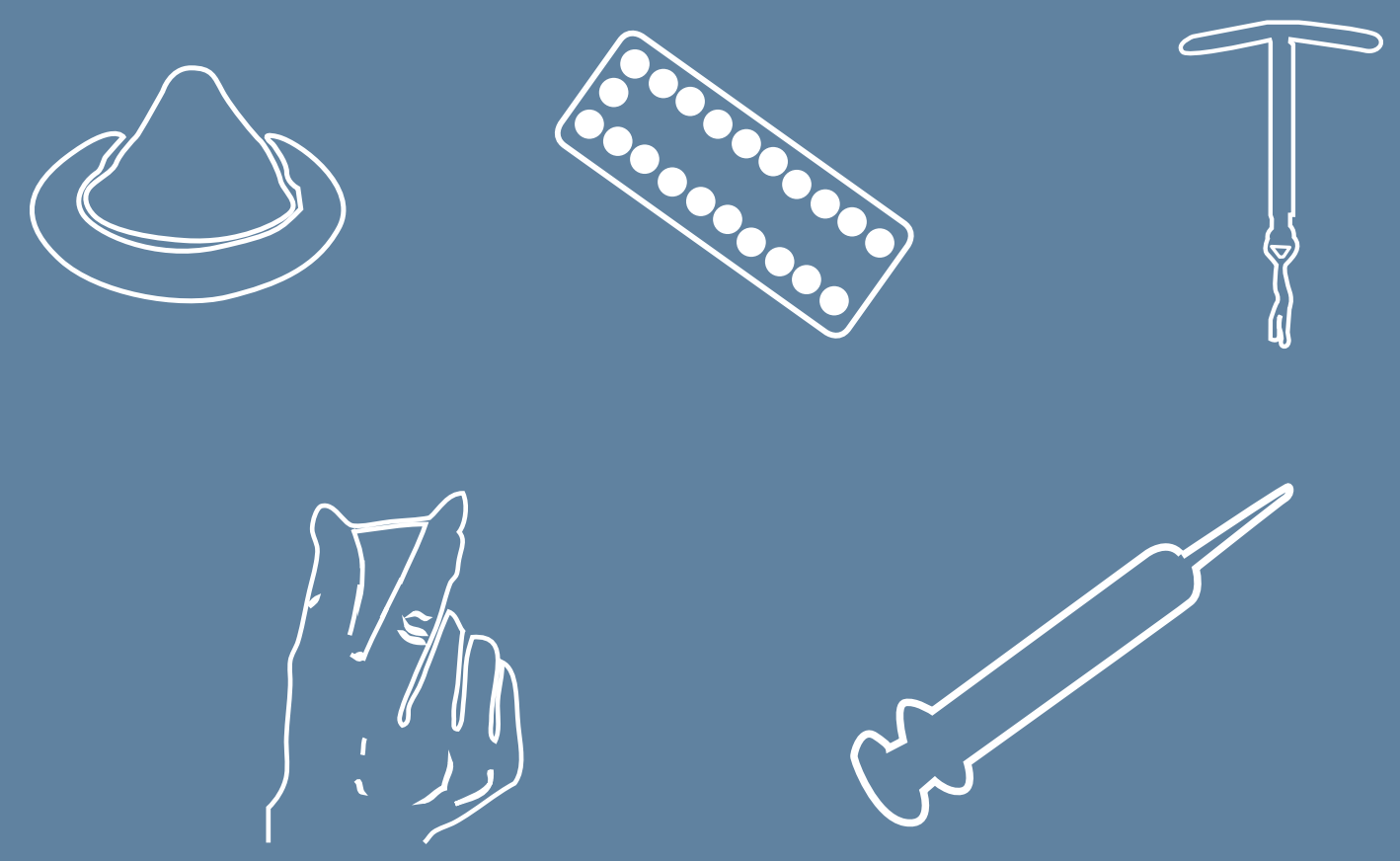


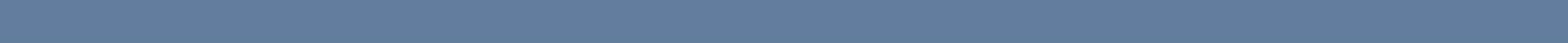




\section{Limited Options: Women Living With HIV and Contraception}

Like all women, people living with HIV have a right to determine the number and timing of their children. WLHIV should have the means to prevent unwanted and poorly timed pregnancies, as well as have children when they desire. To exercise this right, adequate family planning services should be accessible to all WLHIV. While most contraceptive methods are appropriate for WLHIV, contraceptive counseling and guidance are needed to assist women in making informed choices. Family planning counseling for WLHIV should consider disease stage, treatment situation, lifestyle, and personal desires for reproduction. Additionally, counseling for WLHIV should pay special attention to guarding against the transmission of HIV and other STIs by emphasizing dual protection-methods that prevent unplanned pregnancy and the transmission of HIV and other STIs.

Several WLHIV wanted to stop or delay childbearing. Some continued to fear transmitting the virus to their child; others said that they were finished having children or that they wanted to delay having children until sometime in the future. For these women, information about safe and effective methods of contraception was critical. Unfortunately, little information was available to them.

For WLHIV in Egypt, the only contraceptive method available is the condom. This provider's assurances aside, the interviews conducted for this study revealed that relying on condom use alone to prevent unintended pregnancy is not realistic.

In some cases it was clear that the WLHIV and their husbands were not using condoms correctly, sometimes resulting in condom rupture and unintended pregnancy. Interviews also revealed that women often lack the autonomy and negotiating skills to demand condom use during sexual intercourse. Several of the WLHIV said they were not able to control the frequency or quality of condom use by their husbands. One WLHIV described how she repeatedly asked her

4 We do not discuss family planning. If she is living with HIV and regardless of whether her husband is living with the virus or not, he will wear a condom, which would also protect against unwanted pregnancy.

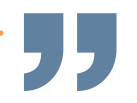

(NGO service provider)

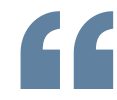

My husband does not use the condom at all, I know this is a big risk for him, as I am sick and he is not.

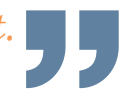

(WLHIV, 28 years) husband to use condoms, but he refused. 
Inconsistent and incorrect use of condoms, when not paired with a reliable contraceptive method, can lead to unintended pregnancy. According to the health care providers, unintended pregnancy is common for WLHIV. One service provider stated that about 80 percent of pregnancies among WLHIV are unplanned. The service provider attributed this to inconsistent use of condoms. According to one WLHIV, unintended pregnancy causes months of emotional stress as a pregnant woman agonizes over the thought that her child might be born HIV-positive. The stress led one WLHIV to self-medicate to cause an abortion in order to avoid having an HIV-positive child.

Another WLHIV got pregnant only four months after giving birth. The strain of a second pregnancy so soon after her previous one took a serious toll on her health. Her doctor recommended that she undergo sterilization after delivering her second child. This is an extreme example of WLHIV suffering the consequences of receiving faulty information from uninformed providers who make decisions that permanently affect those women's lives. It is worth noting that this WLHIV admitted that she thought sterilization was her only option to avoid another unplanned pregnancy and having an HIV-positive child (see Case Study 3).

\section{Case Study 3: Noha}

Noha was 25 years old when she was diagnosed as HIV-positive during routine preoperative testing. She was single at the time and the laboratory technician who gave her the diagnosis asked her many questions about her marital status, virginity, and sexual relations. Noha felt unable to disclose her HIV status to her family because of the stress caused by the recent deaths of her two brothers. "I cannot tell anyone I have that disease because it is linked with illegitimate practices and I will be stigmatized," she said. "Even the doctor has no idea about modes of transmission and is terrified to deal with us." For one and a half years following her diagnosis she kept her status a secret and fell into a state of shock and deep depression.

Now Noha is 28 years old and has been married to a man who is HIV-negative for two years. Her husband was very supportive when she disclosed her HIV status to him. Although they used condoms a few times, Noha's husband did not like them and has since refused to wear them. "My husband is convinced that transmission of the infection from the woman to the man is difficult. He used the condom three to four times. [He] did not like it and refuses to use it."

When Noha became pregnant two months after marriage she considered having an abortion for fear of having an HIV-positive child, but her husband convinced her to keep 
the baby. Noha received PMTCT medication from NAP and routine antenatal care from a private doctor without disclosing her HIV status. She delivered by cesarian section performed by a doctor at a fever hospital who knew her HIV status, but she was treated poorly and neglected by nurses.

Following the birth of her last child, Noha experienced severe anxiety that required treatment from a psychiatrist. Although she is relieved that her child is HIV-negative, she still worries that her own health will deteriorate and she will be unable to care for him. Noha became pregnant again only four months after giving birth to her first child.

During the second pregnancy, Noha developed severe anemia and her CD4 count fell to low levels. She again considered an abortion to avoid the stress of not being sure if her child will be born positive or negative. Instead, she has decided to deliver this baby and have a tubal ligation during the delivery by cesarian section, to prevent future pregnancies. Her doctor is supportive of this decision and has assured her that this is the most effective method to prevent any further pregnancy.

The PLHIV interviewed for this study admitted to having limited knowledge of family planning methods. Apart from condom use, many WLHIV struggled to identify any other method, such as pills or injections, to prevent pregnancy. Most said that they were interested in learning about other contraceptive methods that might be a better fit for their HIV-positive status and reproductive goals.

However, many expressed concern over starting this conversation with health care providers. They said that doing so would lead to having to disclose their HIV status or condom use, which would invite stigma and discrimination. Nevertheless, some women said that they understood the potential for problems with condom use as a contraceptive method; hence they continued to use the
14 I don't know if people like us should be using a family planning method, we will check with staff at the Ministry (MOHP). If they say we can use [it], we will. (HIV-positive man, 38 years)

c6 I wish I could find someone to prescribe a contraceptive method for me and who is aware of my HIV status,

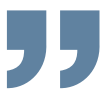

(WLHIV, 31 years)

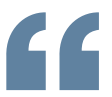
WLHIV are afraid of the stigma so they cannot ask about contraception, (NGO service provider) 
family planning methods they used prior to being diagnosed with HIV without the guidance of a physician.

In addition to stigma-driven self-censorship, WLHIV consistently reported difficulty identifying doctors willing to provide information about methods of contraception other than condoms. Most service providers admitted that their knowledge of the SRH needs of WLHIV was limited largely to condom use and PMTCT. They also were unsure about the

41 Pills and injectables contain hormones that could further damage her already sick liver, while the loop (intrauterine device) increases blood loss [and] hence increases the likelihood of HIV infection,

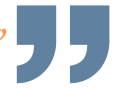

(NGO service provider) availability of family planning methods that would be suitable for WLHIV without contraindications related to their HIV status or to their use of ARVs.

There was a unanimous conviction among providers that condoms were the most appropriate and safe contraceptive method for WLHIV, because they provide dual protection. In their practices, they emphasized the use of condoms to protect against HIV reinfection and STIs. Several stated that when condoms are used correctly and consistently they protect against unintended pregnancy so there is no need to discuss other family planning methods. In fact, many of the interviewed service providers did not believe that it was their duty to provide family planning services other than condoms. One provider mentioned that her job was to help women not pass the virus to their children, but not to prevent unintended

4 The family planning service that we offer is the distribution of condoms; we do not have the capacity to do more,

(NGO service provider) pregnancy.

The experiences described by the WLHIV interviewed for this study echo the findings of research from the MENA region (UNAIDS 2012) and other areas. It shows that WLHIV, like other women, may wish to plan pregnancy, limit their family size, or avoid getting pregnant. Obstacles to pregnancy prevention, such as difficulties in negotiating condom use or other forms of contraception and sexual violence, may result in unintended pregnancies in some HIV-infected women (de Bruyn 2002). Additionally, the lack of reliable information and limited access to providers who are well informed about family planning methods suitable for WLHIV leaves HIV-positive women vulnerable to unintended pregnancy whether or not they are taking ARVs. 
In Egypt, you cannot have a special facility for PLHIV. That place would be doomed-no one would go there.

(NGO service provider)

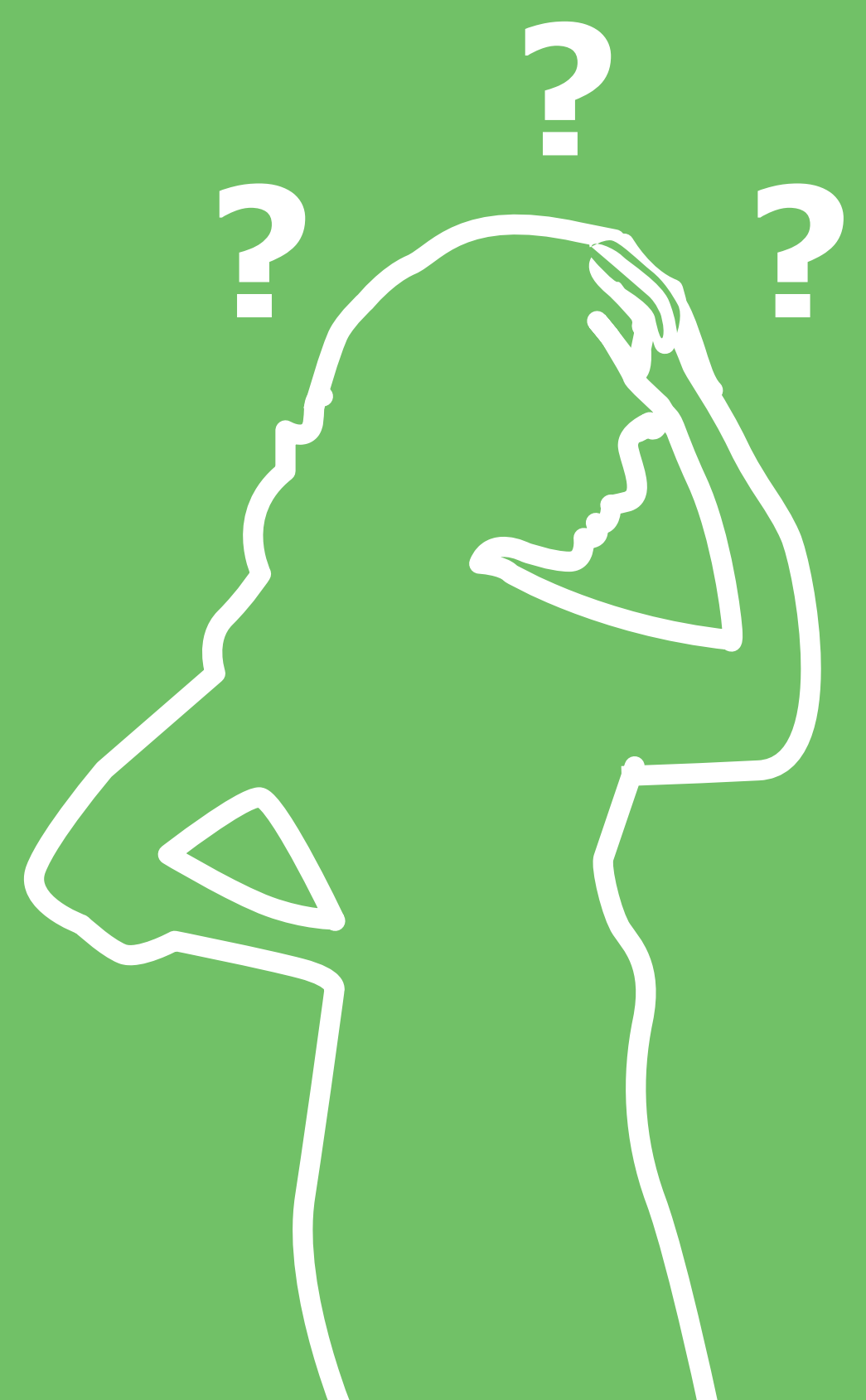





\section{Addressing Sexual and Reproductive Health Needs of Women Living with HIV}

Research from several countries indicates that the SRH needs of WLHIV, and more specifically of pregnant HIV-infected women, are not met for a variety of reasons including stigma and discrimination, provider bias and prejudice, vertical service delivery programs, and the poor quality of reproductive health services in general (Ingram and Hutchin-

What is better is to have a place for everyone where you would go to the doctor and show him your card (that you are HIV-positive) and be treated like everyone else.

(NGO service provider) son 2000; Mahendra et al. 2007; Population Council 2007; Christiana et al. 2008; Gruskin et al. 2008; Myer et al. 2010; MacCarthy et al. 2012). Women living with HIV in Egypt cited antenatal and delivery care, family planning, and services for infected children as the most urgent SRH needs. They reported that accessing SRH services was very difficult. Many encountered a lack of respect and potential breaches of confidentiality when visiting public hospitals and health units. Other women said that they were turned away from numerous service providers upon disclosing their HIV status. Moreover, almost all WLHIV believe that they do not have enough information about their SRH.

Unfortunately, WLHIV must overcome significant barriers to achieve their sexual and reproductive goals. Besides stigma and discrimination, WLHIV have to live with the shortcomings of a vertical health care system that leaves providers in family planning and maternal health care services unaware of the SRH needs of WLHIV. Likewise, those who provide HIV care and support are not trained to provide family planning or maternal health services.

This is a common theme in other countries as well, where reproductive health and HIV programs are run in parallel fashion by separate departments within Ministries of Health, each of which has its own policies, guidelines, training, monitoring, and service delivery structures, with limited coordination (Wilcher and Cates 2010). This vertical structure also perpetuates stigma and discrimination among providers who are unaware of how to address the needs of special populations such as PLHIV.

HIV-care providers who participated in this study confirmed that gaps in their training prohibit them from providing SRH information and services to WLHIV. Most said they had received training in providing HIV counseling in areas such as condom use, healthy living, social and legal support, nutrition, and countering stigma, but they had not received training in providing SRH counseling and services to WLHIV.

On preferences of WLHIV regarding location of SRH services, several of the interviewed women indicated that they were most comfortable receiving comprehensive services from NGOs. On 
the whole, however, the WLHIV interviewed for this study agreed on one thing; they expressed a desire for better access to respectful providers who are willing to care for their needs, regardless of where those services are located.

On the other hand, interviewed providers clarified that NGOs targeting PLHIV are unable to provide SRH services apart from counseling and condom distribution. NGOs do not have the budgetary resources needed to hire and maintain the staff necessary to offer a full range of $\mathrm{SRH}$ services or the required infrastructure. For these reasons, providers from the NGO sector reported that they must refer WLHIV in need of SRH services to other centers, including private health care providers. They also reported that services from private physicians and treatment centers willing to care for PLHIV are expensive and that many WLHIV are not able to afford them.

To adequately address the needs of WLHIV, all participants agreed that some level of service integration is necessary. Research suggests that expanding the range of services provided at one site can improve general service utilization (Foreit, Hardee, and Agarwal 2002) and positively impact the quality of services in terms of the continuation of care and ease of referrals (Ringheim 2012). Reviews of models of integrated RH and HIV services showed positive effects on HIV incidence, STI incidence, condom use, uptake of HIV testing, quality of services, and better health outcomes for PLHIV (Mark et al. 2007; Kennedy 2010; Rogers et al. 2013).

Participants in the present study identified two possible models for delivering high-quality integrated services to WLHIV in Egypt. The first model, complete integration, calls for providing all HIV and SRH services under one roof-a "one stop shop" for WLHIV. WLHIV interviewed for this study preferred this approach, citing their preference for receiving

$4 \mathcal{N G O s}$ are best [because] they know everything about us and we feel better there because at the hospitals once they know that anyone is HIV-positive, they run away.

(WLHIV, 29 years) services from NGOs. While this model offers a high level of convenience by reducing the need for referral and improving the continuum of care, an important factor in the efficacy of a service integration model is demand (Galvao and Halverson 2005). In a low-prevalence setting such as Egypt, the demand for HIV/AIDS services is relatively low compared with other health services. Additionally, health care providers noted that a specialized center for PLHIV might be a target for stigma and discrimination.

Service providers were more inclined toward a "counseling and referral model" where WLHIV would receive basic counseling at HIV-care centers followed by referral to a pre-approved PHC center where staff would be trained to handle the SRH needs of WLHIV in a respectful manner. This model offers the opportunity to coordinate services by offering basic counseling on both HIV/AIDS and SRH information in both types of facilities. 
I need a place that has pregnancy follow-up services, delivery services and where I can find incubators for my child. Even if not allowed at the same place, I would like to know places that offer these services and would accept me when they know my status

(WLHIV, 28 years)

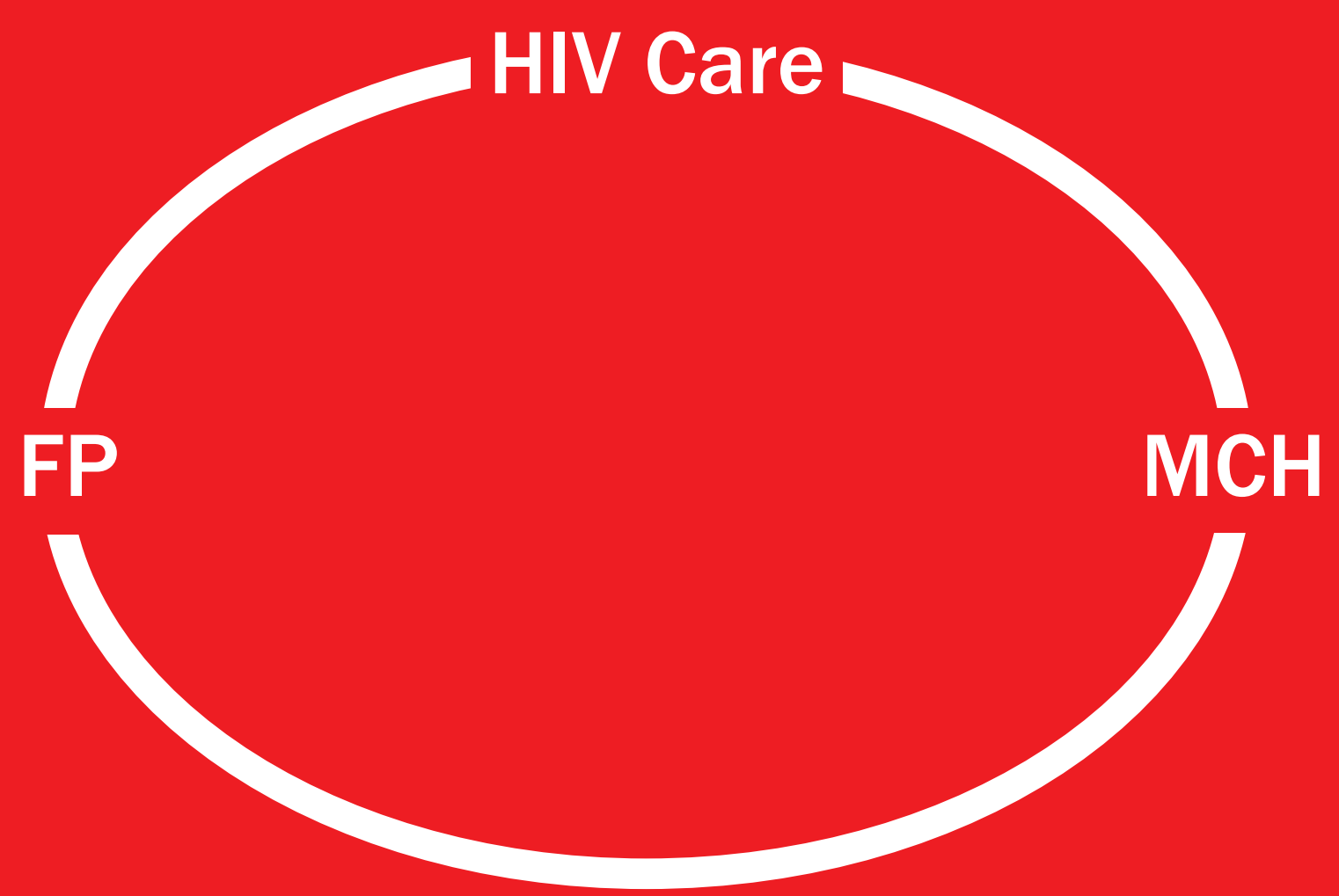





\section{Conclusions and Recommendations}

The SRH needs of WLHIV in Egypt are not dissimilar to those of healthy women in other parts of the world. Just like other women, WLHIV want to have strong marital relationships and enjoy sexual relations free from coercion or the risk of infection. They want the option of delaying or planning pregnancies and, when the time comes, delivering healthy babies. When they seek health care, WLHIV want their provider to acknowledge their health condition and to provide quality guidance and treatment in a respectful manner.

For WLHIV in Egypt, exercising those basic SRH rights is a challenge. Widespread stigma and discrimination among health care providers and at the community level create significant barriers to accessing basic services and deprive many WLHIV of realizing their SRH rights and reproductive goals. Additionally, the current setup of vertical service delivery programs means that staff trained to provide maternal and child health or family planning services are often unaware of and untrained in the needs of WLHIV. Likewise, providers who work in HIV-care centers are not trained in or aware of how to address the unique SRH needs of the WLHIV that they serve.

These circumstances affect the ability of WLHIV to access SRH services. Poor treatment by untrained or uninformed providers makes WLHIV hesitant to seek additional services in the future. Moreover, unreliable access to information perpetuates misconceptions about HIV/ AIDS and the options available to WLHIV. The discrimination and stress these women experienced due to repeated rejection from health care providers not only violated their rights but also jeopardized their health and their chances of successful delivery of a healthy child.

The multiple and interrelated needs of WLHIV would be better addressed through an integrated model of service provision. Research suggests that the counseling and referral model of service integration may be the most feasible and effective in low-HIV prevalence settings such as Egypt. In this model, WLHIV would receive basic counseling on SRH topics from their HIV service provider to be followed by referral to a pre-approved PHC center where staff members are trained to address the specific needs of WLHIV. Because it utilizes existing facilities and staff and does not require the broad expansion of services in one facility, the counseling and referral model may be more cost-effective and feasible in the Egyptian context where demand for specialized SRH services by WLHIV is relatively low. However, piloting of this model through operations research is necessary in order to assess its feasibility, effectiveness, and cost-effectiveness.

Preparing providers for an integrated service model will require training them to address the complex needs of WLHIV with sensitivity and respect. Those providing services at HIV-care 
centers will need training in basic SRH counseling and referrals. Staff at PHC centers will need to receive training in addressing the unique needs of WLHIV and when to refer their patients to HIV/AIDS-care centers. PHC professionals should also receive training in methods of provider-initiated counseling and testing in which, through targeted interviewing of pregnant women, they would identify those most at risk for HIV/AIDS and counsel them on the benefits of testing.

HIV/AIDS-related information should also be integrated into medical and nursing school curricula. This will help to prepare a new generation of providers who are sensitive to the needs of WLHIV. Adequate training that begins early in providers' careers will help them overcome their biases and prejudices. This will reduce the prevalence of stigma and discrimination within the health system and improve access to care for WLHIV.

The widespread stigma and discrimination present at the community level requires broad interventions. Mass media campaigns, for example, public service announcements via television and radio, or informational pamphlets distributed in public places, would help spread accurate information about HIV/AIDS. This type of campaign should include messages relating the lives and needs of PLHIV to the rest of the community, emphasizing their similarities. The mass media campaigns also should focus on dispelling misconceptions about how HIV is transmitted, including the widely held misconception that the virus is linked exclusively to inappropriate behaviors. Finally, these campaigns should clarify the rights of PLHIV to access health services including SRH services.

Last but not least, WLHIV must be empowered to demand and exercise their SRH rights. They should receive training to build their knowledge of basic SRH information, human and legal rights, and advocacy methods. These women could then provide information and guidance to other WLHIV above and beyond that of local support groups. They could also advocate for more comprehensive and dignified services that would enable WLHIV to exercise their SRH rights and realize their reproductive goals. 




\section{REFERENCES}

Anderson, Jean R. (ed.) 2001. A Guide to the Clinical Care of Women with HIV. Rockville, MD: HRSA, HIV/AIDS Bureau.

Brouard, P. and Wills, C. 2006. "A closer look: The internalization of stigma related to HIV." POLICY Project, Centre for the Study of AIDS/University of Pretoria and USAID.

Christiana, M., Gordillo, V., Borms, R., et al. 2008. "Differences in perceptions on sexual and reproductive health between service providers and people living with HIV: A qualitative elicitation study," Psychology, Health \& Medicine Journal, 13(5): 516-528.

de Bruyn, M. 2002. "Reproductive choice and women living with HIV/AIDS." Chapel Hill, NC: Ipas.

EngenderHealth and UNFPA. 2006. "Sexual and reproductive health needs of women and adolescent girls living with HIV. Research report on qualitative findings from Brazil, Ethiopia and the Ukraine." EngenderHealth/UNFPA.

Foreit, K., Hardee, K., and Agarwal, K. 2002. "When does it make sense to consider integrating STI and HIV services with family planning services?" International Family Planning Perspectives, 28(2). http://www.guttmacher.org/pubs/journals/2810502.html. Accessed 5 August 2014.

Galvao, J. and Halverson, J. 2005. "Integration of HIV/AIDS and family planning," The Lancet, 366 (9491): 1076-1077.

Goffman, E. 1963. Stigma: Notes on the Management of a Spoiled Identity. New York: Simon and Schuster.

Gruskin, S., Firestone, R., MacCarthy, S., and Ferguson L. 2008. "HIV and pregnancy intentions: Do services adequately respond to women's needs?" American Journal of Public Health 98(1746-1750). doi:10.2105/AJPH.2008.137232.

Ingram, D. and Hutchinson, S.A. 2000. "Double binds and the reproductive and mothering experiences of HIV-positive women," Qualitative Health Research 10(1): 117-132.

Kennedy, C., Spaulding, A., Brickley, D., et al. 2010. "Linking sexual and reproductive health and HIV interventions: A systematic review," Journal of the International AIDS Society 13: 26. 
Khattab, H., et al. 2007. "All alone: The stories of Egyptian women living with HIV, stigma and isolation." Cairo: Egyptian Society for Population Studies and Reproductive Health (ESPSRH).

—. 2010. "The agony of AIDS: A qualitative study of the experience of AIDS in Egypt." Cairo: Egyptian Society for Population Studies and Reproductive Health (ESPSRH).

MacCarthy, S., Rasanathan, J., Ferguson, L., and Gruskind, S. 2012. “The pregnancy decisions of HIV-positive women: The state of knowledge and way forward," Reproductive Health Matters 20(39S): 119-140.

Mahendra, S., Mudoi, R., Oinam, A., et al. 2007. "Continuum of care for HIV-positive women accessing programs to prevent parent-to-child transmission: Findings from India. Horizons Final Report. Washington, DC: Population Council.

Mark, K., Meinzen-Derr, J., Stephenson, R., et al. 2007. "Contraception among HIV concordant and discordant couples in Zambia: A randomized controlled trial," Journal of Women's Health 16(8): 1200-1210.

Ministry of Economic Development and the United Nations Development Program.2010. Egypt's Progress towards Achieving The Millennium Development Goals. Cairo: Ministry of Economic Development.

Ministry of Health and Population in collaboration with Family Health International and Center for Development Services. 2010. “Egypt Biological and Behavioral Surveillance Survey, Summary Report". Cairo: Ministry of Health and Population.

Myer, L., Carter, R.J., Katyal, M., et al. 2010. “Impact of antiretroviral therapy on incidence of pregnancy among HIV-infected women in sub-Saharan Africa: A Cohort Study," PLoS Med 7(2): e1000229. doi:10.1371/journal.pmed.1000229.

National AIDS Program (NAP) 2013. "A guideline for clinical management of HIV/AIDS and ARVs." Cairo: Ministry of Health and Population.

Perchal P., Farrell B. and Osborne K.2006. Responding to the Sexual and Reproductive Rights of PLHIV. Available at: http://www.engenderhealth.org/files/pubs/hiv-aids-stis/aidslink-engenderhealth-article.pdf

Population Council. 2007. "Reproductive health and rights of HIV-positive individuals: Establishing a global program." New York: Population Council. 
Ringheim, K. 2012. "Better together: Linking family planning and community health for health equity and impact." Washington, DC: CORE Group.

Rogers, S., De Palomo, F., Little, S., and Woldehanna, S. 2013. "Testing a service integration model: Results from the HIV/AIDS initiative, Connect HIV," AIDS Care 25(3): 317-325.

UNFPA. 1994. "Programme of action of the International Conference on Population and Development." Available at:

http://www.unfpa.org/public/cache/offonce/home/sitemap/icpd/International-Conferenceon-Population-and-Development/ICPD-Programme;jsessionid=6E40AC8CA8EB1835C926CC 3BCF532C78.jahia01\#ch7.

United Nations Joint Programme on HIV/AIDS (UNAIDS). 2012. "Standing up speaking outWomen and HIV in the Middle East and North Africa." Issue Brief. Cairo: UNAIDS.

—. 2013. "Regional report for the Middle East and North Africa." Geneva: UNAIDS.

2014. A focus on women: A key strategy to preventing HIV among children. Issue Brief. Geneva: UNAIDS.

Voices of Positive Women (VOPW). 2004. “Life goes on: Pregnancy and HIV.” Toronto: Voices of Positive Women.

Wilcher, R. and Cates, W. 2010. "Reaching the Underserved: Family Planning for Women with HIV." Studies in Family Planning 41 (2).

World Health Organization (WHO). 2010. "Antiretroviral drugs for treating pregnant women and preventing HIV infection in infants: Recommendations for a public health approach. Geneva: WHO

WHO and UNFPA 2006a. "Glion consultation on strengthening the linkages between reproductive health and HIV/AIDS: Family planning and HIV/AIDS in women and children" Available at: http://www.who.int/hiv/pub/advocacymaterials/glionconsultationsummary_DF.pdf?ua=1.

- 2006b. "Sexual and reproductive health of women living with HIV/AIDS: Guidelines on care, treatment and support for women living with HIV/AIDS and their children in resourceconstrained settings. WHO: Geneva. 


Population Council/Egypt

59 Misr-Helwan Agricultural Road,

Maadi

Po Box 168, Maadi

Cairo, Egypt

11431

Tel. +20225255968

Fax: +20 225255962

Ideas. Evidence. Impact. 